\title{
Study on Water Ridge Variation of Horizontal Wells in Bottom Water Reservoir
}

\author{
Xiujuan Zhao, Mo Zhang, Quanlin Wang, Jie Tan, Bo Li \\ Bohai Oilfield Research Institute, Tianjin Branch of CNOOC Ltd., Tianjin, China \\ Email:16890452@qq.com
}

How to cite this paper: Zhao, X.J., Zhang, M., Wang, Q.L., Tan, J. and Li, B. (2020) Study on Water Ridge Variation of Horizontal Wells in Bottom Water Reservoir. Journal of Power and Energy Engineering, 8, 43-54.

https://doi.org/10.4236/jpee.2020.810004

Received: September 5, 2020

Accepted: October 26, 2020

Published: October 29, 2020

Copyright $\odot 2020$ by author(s) and Scientific Research Publishing Inc. This work is licensed under the Creative Commons Attribution International License (CC BY 4.0).

http://creativecommons.org/licenses/by/4.0/

\begin{abstract}
$\mathrm{X}$ oilfield is a typical strong bottom water reservoir in Bohai Sea. It is developed by single sand body horizontal well. The edge and bottom water of the reservoir is active and natural energy development mode is adopted. At present, the comprehensive water cut of the oilfield is more than $96 \%$, and has entered the stage of high water cut oil recovery. At present, fluid extraction from old wells and new adjustment wells are the main ways to increase oil production. With the deepening of development, the distribution of underground remaining oil is becoming more and more complex. In order to further improve the implementation effect of adjustment wells, the study of residual oil distribution law is increasingly important, and the study of water ridge morphology of horizontal wells in bottom water reservoir has an important guiding role in the study of remaining oil distribution. The main contents of this paper are as follows: the influence of horizontal well spacing, vertical and horizontal permeability ratio, single well liquid production, vertical position of horizontal well, oil-water viscosity ratio, water cut and interlayer on water ridge morphology. These understandings can effectively guide the deployment and optimization of adjustment wells. It provides technical support for the prediction of watered out thickness and optimization of adjustment well layout scheme in X oilfield, and guides the further development and production of the oilfield.
\end{abstract}

\section{Keywords}

Bottom Water Reservoir, Horizontal Well, Water Ridge Rising Height, Water Ridge Range

\section{Preface}

Horizontal well is an important technology to increase the production of single well by expanding the oil drainage area of reservoir, so as to improve the eco- 
nomic benefit of oilfield development. There are also some problems to be solved in the development of bottom water reservoirs by horizontal wells. However, the existing studies mainly focus on the analysis and characterization of the development of water ridge morphology, and lack of research on the influence of various factors on the shape of water ridge; especially the interaction between various factors is ignored. Based on the actual reservoir parameters of $\mathrm{X}$ oilfield, this paper establishes a numerical conceptual model, and analyzes the influence of horizontal well spacing, vertical and horizontal permeability ratio, single well fluid production, vertical position of horizontal well, oil-water viscosity ratio, water cut and interlayer on water ridge morphology. Through the sensitivity analysis of numerical simulation and the orthogonal experimental design method [1]-[8], the significant degree of the influence of various factors and their interaction on the shape of water ridge is analyzed [9]-[15].

\section{Establishment of Mechanism Model}

Based on the basic data of $\mathrm{X}$ oilfield parameters, this paper establishes a basic model, then changes the values of parameters on the basis of the basic model, analyzes the influence of each parameter on the development effect of bottom water reservoir, qualitatively explains the relationship between recovery degree and various influencing factors, and analyzes the sensitive factors affecting the development effect.

The model can not only directly observe the bottom water inrush, but also comprehensively consider the inter well interference. The model adopts a uniform grid system of $90 \times 90 \times 20$. Other parameters of the basic model are: water oil volume ratio of 100 , reservoir thickness of $15 \mathrm{~m}$, porosity of $30 \%$, horizontal permeability of $3000 \mathrm{mD}$, vertical permeability of $300 \mathrm{mD}$, initial oil saturation of 0.75 , formation oil viscosity of $30 \mathrm{mPa} \cdot \mathrm{s}$, crude oil density of $950 \mathrm{~kg} / \mathrm{m}^{3}$, apparent viscosity of formation water of $0.45 \mathrm{mPa} \cdot \mathrm{s}$, and formation water density of $1000 \mathrm{~kg} / \mathrm{m}^{3}$. The production wells are 3 horizontal wells without water injection wells. The initial horizontal well perforation layer is the second layer, the horizontal well length is $300 \mathrm{~m}$, and the initial well spacing is $300 \mathrm{~m}$ (Figure 1). The oil-water relative permeability curve used in the model is shown in Figure 2.

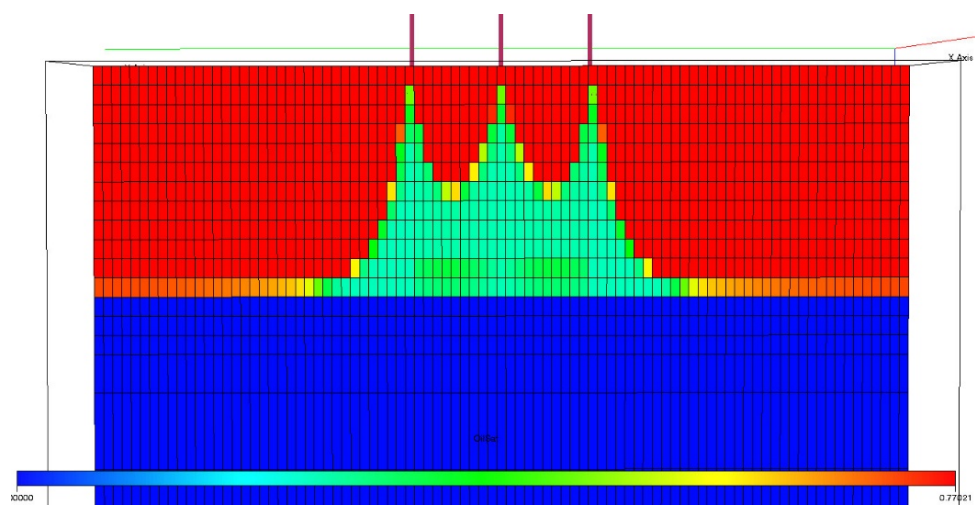

Figure 1. Section screenshot of mechanism model. 


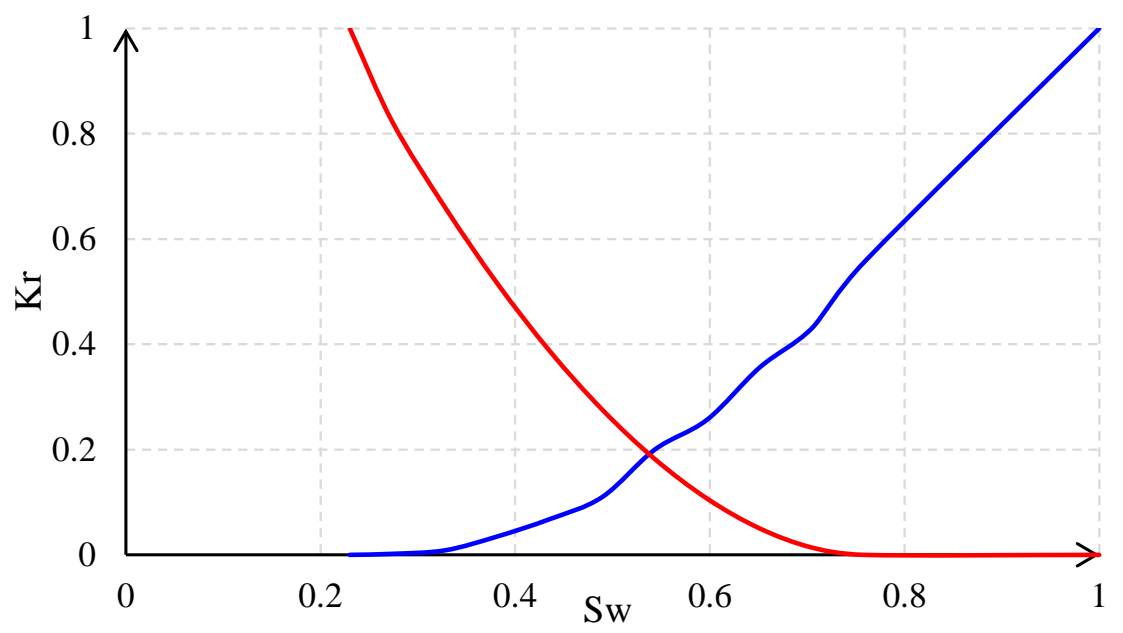

Figure 2. Mechanism model phase permeability curve.

\section{Analysis of Influencing Factors}

Through investigation, the influencing factors of water ridge shape include: horizontal well spacing, vertical/horizontal permeability ratio, liquid production rate, horizontal well position, oil-water viscosity ratio, water cut, and interlayer. In this paper, through the mechanism model, the influence of various factors on the shape of water ridge is analyzed.

\subsection{Influence of Well Spacing}

The design well spacing ranges from $100 \mathrm{~m}$ to $500 \mathrm{~m}$ in the scheme study. According to the results, with the increase of well spacing, the maximum water ridge radius gradually decreases, the percentage of remaining oil reserves in geological reserves also increases, and the development effect becomes worse. Therefore, infill well pattern within reasonable well spacing can effectively enhance oil recovery and improve development effect (Figure 3).

\subsection{Influence of Permeability Ratio}

In the research scheme, we set the ratio of vertical horizontal permeability to $0.01,0.05,0.1,0.2,0.5$ and 1 respectively to study the volume morphology of water ridges under different $\mathrm{K}_{\mathrm{v}} / \mathrm{K}_{\mathrm{h}}$ ratios. The results show that the higher the $\mathrm{K}_{\mathrm{v}} / \mathrm{K}_{\mathrm{h}}$, the higher the water cut and the worse the development effect. This is because the higher the vertical permeability is, the smaller the vertical resistance is. Under the smaller production pressure difference, the bottom water can be ridged upward, and the faster the bottom water rises, the faster it reaches the bottom of the well; the smaller the $\mathrm{K}_{\mathrm{v}} / \mathrm{K}_{\mathrm{h}}$, the greater the vertical seepage resistance of the reservoir is, and the pressure can fully propagate in the horizontal plane, and the area of bottom water action increases, but it will not coning along the wellbore rapidly.

Under the scheme of ratio of vertical permeability to horizontal permeability, the variation law of parameter values with permeability ratio is observed. The 


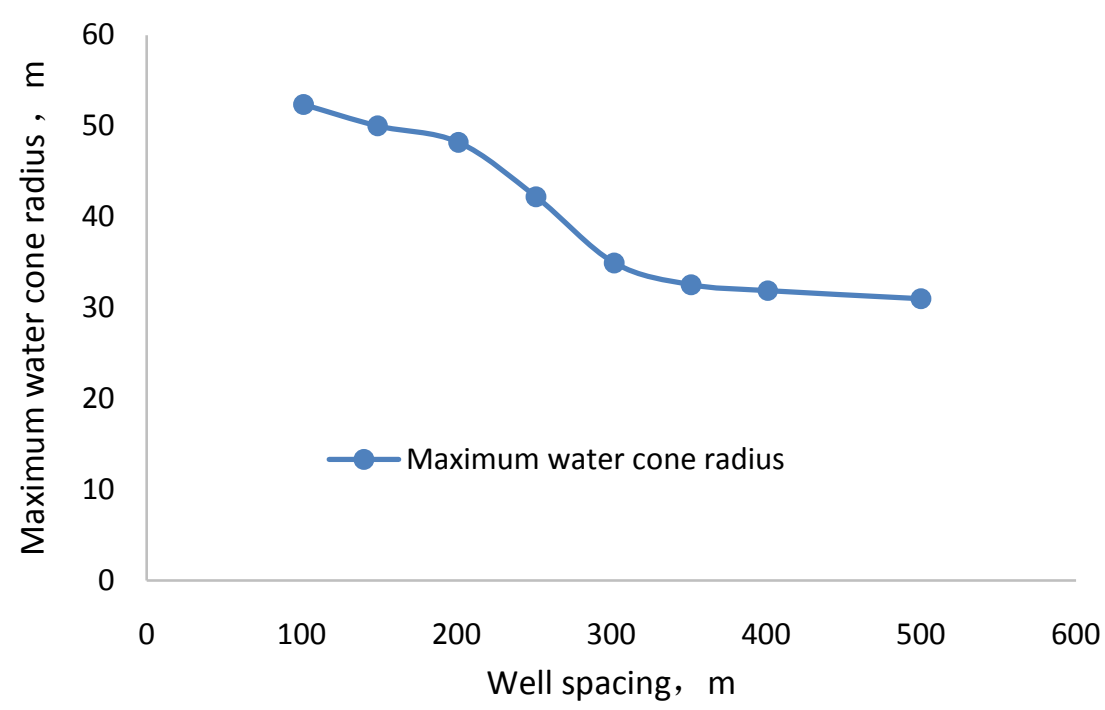

Figure 3. Variation chart of well spacing and water ridge radius.

smaller the ratio of vertical permeability to horizontal permeability is, the greater the vertical seepage resistance is, and the pressure can fully propagate in the horizontal plane, and the larger the horizontal swept area is, and it will not coning along the wellbore rapidly. Therefore, the smaller the ratio of vertical permeability to horizontal permeability is, the larger the maximum water ridge radius is (Figure 4).

\subsection{Influence of Liquid Production Rate}

The designed liquid production rate is set at 50,100, 150, 200, 300 and $500 \mathrm{~m}^{3} / \mathrm{D}$ respectively. According to the results of numerical simulation, the recovery degree of heavy oil reservoir with bottom water increases with the increase of liquid production rate. From this law, we can analyze that for the heavy oil reservoir with bottom water in $\mathrm{X}$ oilfield, the liquid production rate can be appropriately increased, that is, increase the differential pressure production and develop at a high speed, so as to obtain economic benefits earlier.

Based on the mechanism model, the influence of liquid production rate on the shape of water ridge is simulated. The calculation results show that when the liquid production rate is small, the production pressure difference is small, and the maximum water ridge radius increases with the increase of liquid production rate. However, because the formation crude oil is heavy oil, the water ridge volume is not clear, and the overall trend is upward, and there is a maximum value, and the water ridge shape is higher than a certain liquid production rate The states are slightly reduced (Figure 5).

\subsection{Influence of Horizontal Well Location}

In order to study the influence of horizontal well position on oil recovery, six schemes of horizontal well position of $0.9 \mathrm{~h}, 0.8 \mathrm{~h}, 0.7 \mathrm{~h}, 0.5 \mathrm{~h}, 0.3 \mathrm{~h}$ and $0.2 \mathrm{~h}$ are simulated and calculated respectively. It can be seen from the numerical 


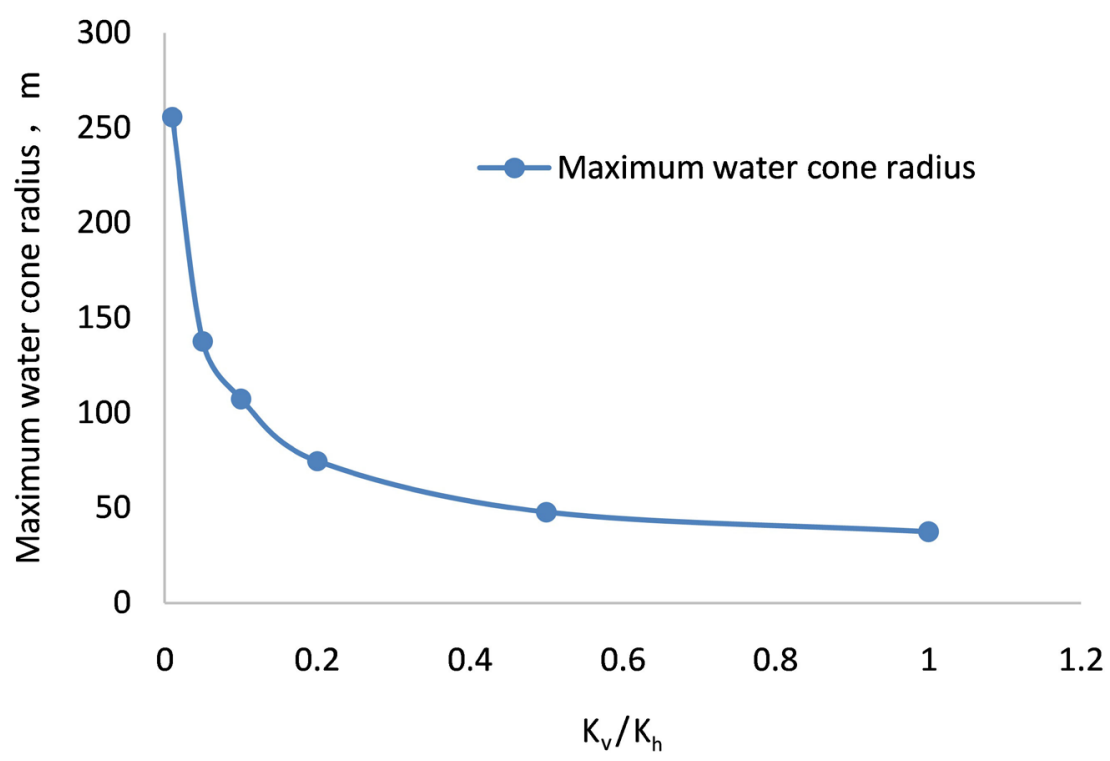

Figure 4. Variation of permeability ratio and water ridge radius.

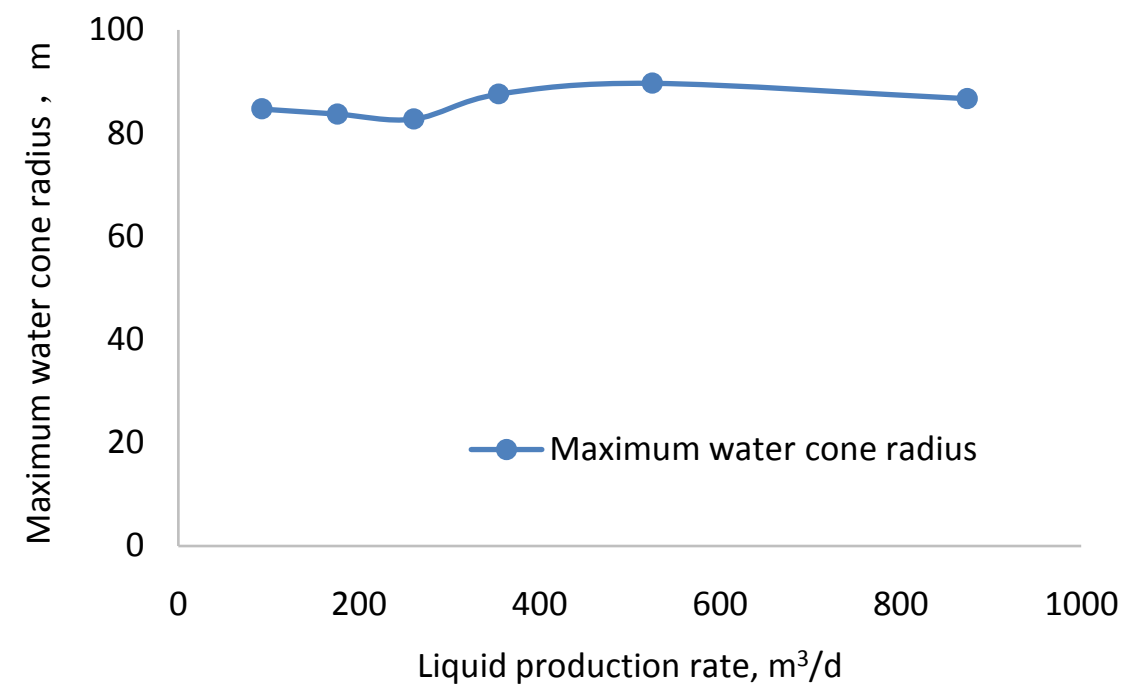

Figure 5. Liquid production rate and water ridge radius variation.

simulation results that when the same recovery degree is reached, the greater the distance from the top, the greater the water cut, and the earlier the water breakthrough time of the oil well, the water free recovery degree will be significantly reduced, and the development effect will be worse. This is because the nearer the horizontal well is to the bottom water, the bottom water will rise rapidly, resulting in water breakthrough in the oil well; however, if the opening degree is too small, the liquid supply will be insufficient. Therefore, the horizontal well should be drilled to the top of the reservoir.

The research shows that the closer the horizontal well is to the bottom water, the bottom water will quickly cone into the bottom of the well, the water breakthrough will be early, the water cut will rise quickly, and the radius of water ridge will be smaller (Figure 6). 


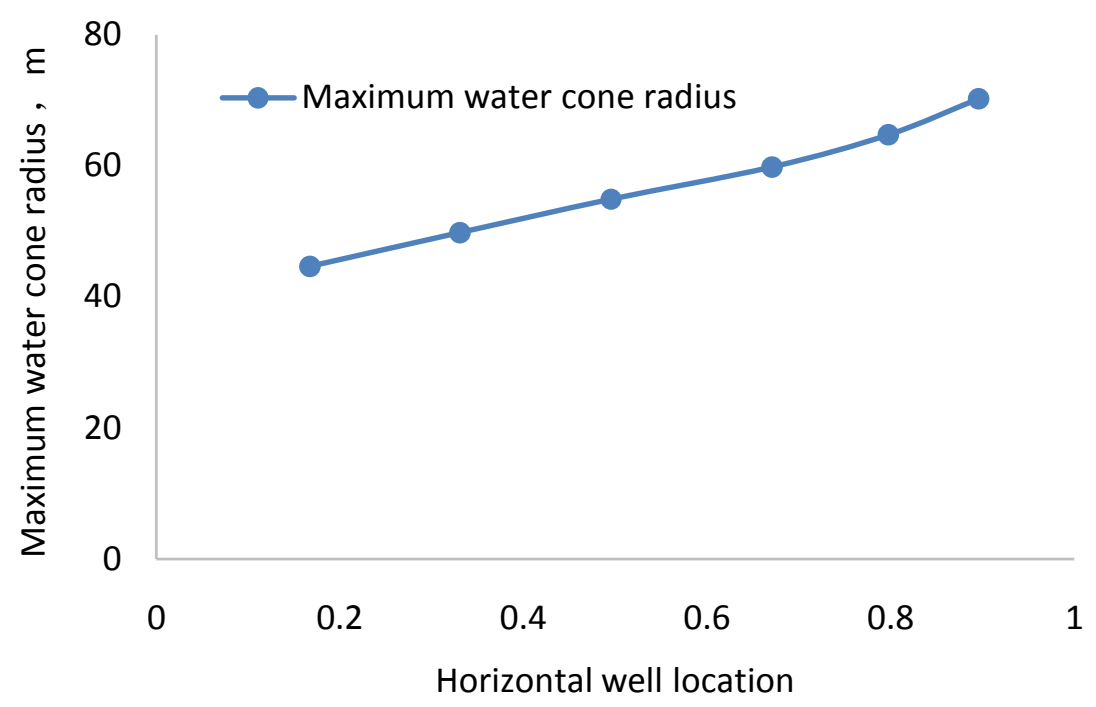

Figure 6. Change of height of avoiding water and radius of water ridge.

\subsection{Effect of Crude Oil Viscosity}

In order to better study the effect of oil-water viscosity ratio on water ridge morphology, the actual viscosities of sand bodies in $\mathrm{X}$ oilfield are selected for numerical simulation calculation. The crude oil viscosities are 30, 80, 200, 350 and $500 \mathrm{mPa} \cdot \mathrm{s}$, and the parameters related to crude oil viscosity, such as crude oil density, volume coefficient, dissolved gas oil ratio and saturation pressure, are modified. According to the results of numerical simulation, the viscosity of crude oil has a significant effect on the shape of water ridges. With the increase of crude oil viscosity, the anhydrous oil recovery period decreases, and the recovery degree under the same water content is greatly reduced. The reason is that when the crude oil viscosity is low, the gravity effect is strong, which effectively inhibits the coning of bottom water. Moreover, when the crude oil viscosity is low, the bottom water is more evenly pushed forward, and the water ridge sweep range is wide and the height is small. On the contrary, the scope of water ridge is small, the height of water ridge is greatly increased, and the shape of water ridge changes obviously.

The shape and size of water ridges were calculated by mechanism model. When the crude oil viscosity is small, the oil-water fluidity is small, which is close to the piston type oil displacement, the water is relatively uniform and the water ridge range is large (Figure 7).

\subsection{Influence of Water Cut}

With the continuous development of the oilfield, the water cut of the oil well will be higher and higher, and the water ridge will be larger and larger (Figure 8).

\subsection{Influence of Interlayer}

The interlayer is an impermeable rock layer that can block the fluid movement in the process of oilfield development. From the research of reservoir engineering, 


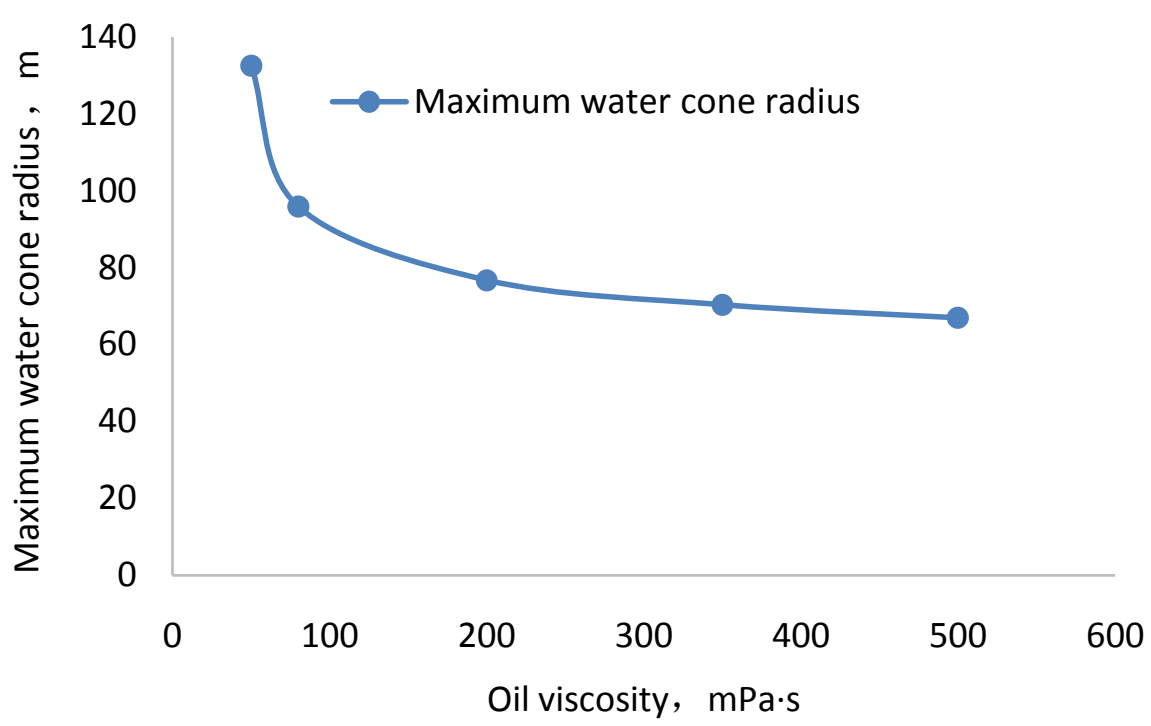

Figure 7. Oil water viscosity ratio and water ridge radius variation.

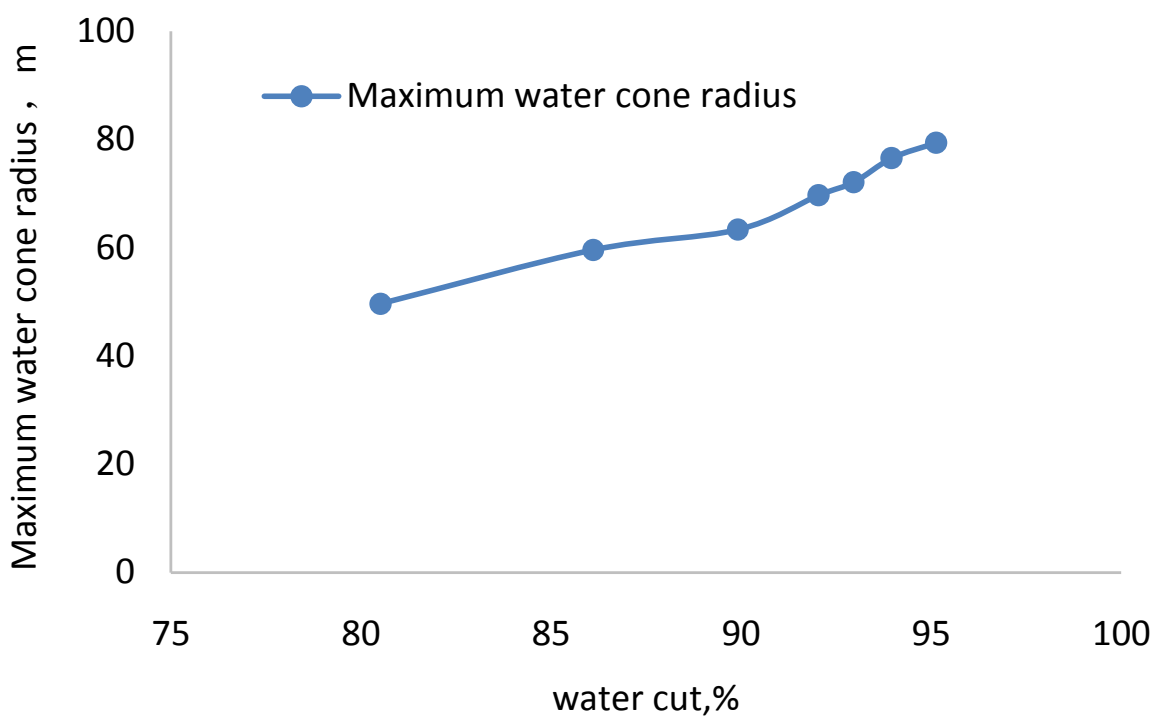

Figure 8. Change of water content and ridge radius.

the interlayer has a certain inhibition effect on the bottom water cone (ridge). The research on the rising law of water ridge by the interlayer is also helpful to recognize the distribution of remaining oil and guide the deployment of adjustment wells.

1) Influencing factors of interlayer position

The influence factors of interlayer position continue to use the above mechanism model to study, and five different interlayer positions are selected, namely no interlayer, intermediate layer and top layer. As can be seen from Figure 9, when the interlayer size is fixed, the development effect is better with the increase of interlayer distance from oil-water interface; under the same recovery degree, the higher the interlayer distance from the oil-water interface, the higher the water cut the slower the speed. In addition, it is also found that there is a residual oil 


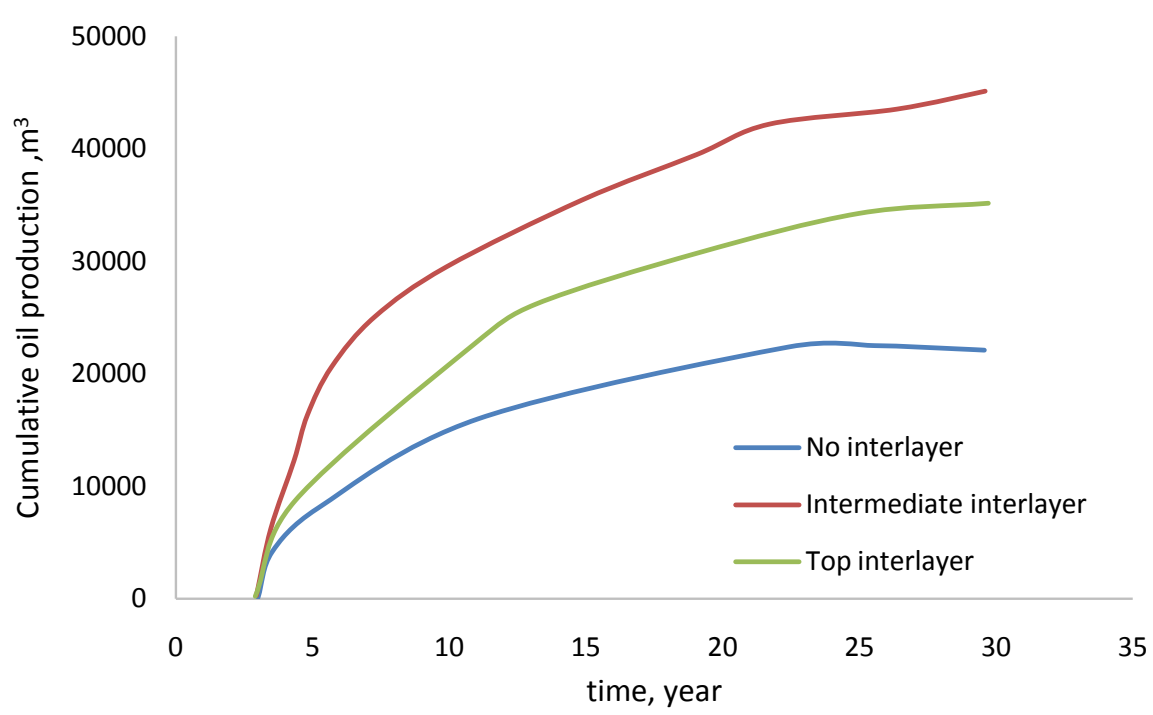

Figure 9. Cumulative oil production in different interlayer positions.

enrichment area in the lower part of the interlayer near the horizontal well and far away from the oil-water interface, which can be used as the key area for tapping the remaining oil in the high water cut stage of the reservoir (see Figure $10)$.

2) Influencing factors of interlayer size

In the mechanism model, we fixed the interlayer in the middle of the oil layer, and designed three schemes. The interlayer area accounts for $1 \%, 5 \%$ and $8 \%$ of the whole layer area respectively. It can be seen from Figure 11 that the larger the interlayer distribution range is, the slower the water cut rises, the stronger the shielding effect of interlayer on bottom water, the higher the recovery degree, and the better the development effect.

\section{Weight Analysis of Influencing Factors}

The rationality of reservoir development is determined by many factors. Therefore, after the single factor analysis of influencing water ridge shape, this study also analyzes the rising law of water ridge under the above-mentioned multiple factors. The method used is orthogonal experimental design.

Firstly, the factor levels of orthogonal test design are determined. Five factors are: well spacing, permeability ratio, liquid production rate, horizontal well position and oil-water viscosity ratio. Three levels are selected for each factor. The orthogonal test factor level table is shown in Table 1.

After selecting the experimental value of the factor level, the orthogonal experimental design scheme is drawn out according to the orthogonal table. For each test scheme, numerical simulation software is used to predict the corresponding results.

After obtaining the results of orthogonal experiment design, we conducted range and variance analysis on the test results, and obtained the primary and secondary order of the influence of various factors on the test indexes, as shown in Table 2. 


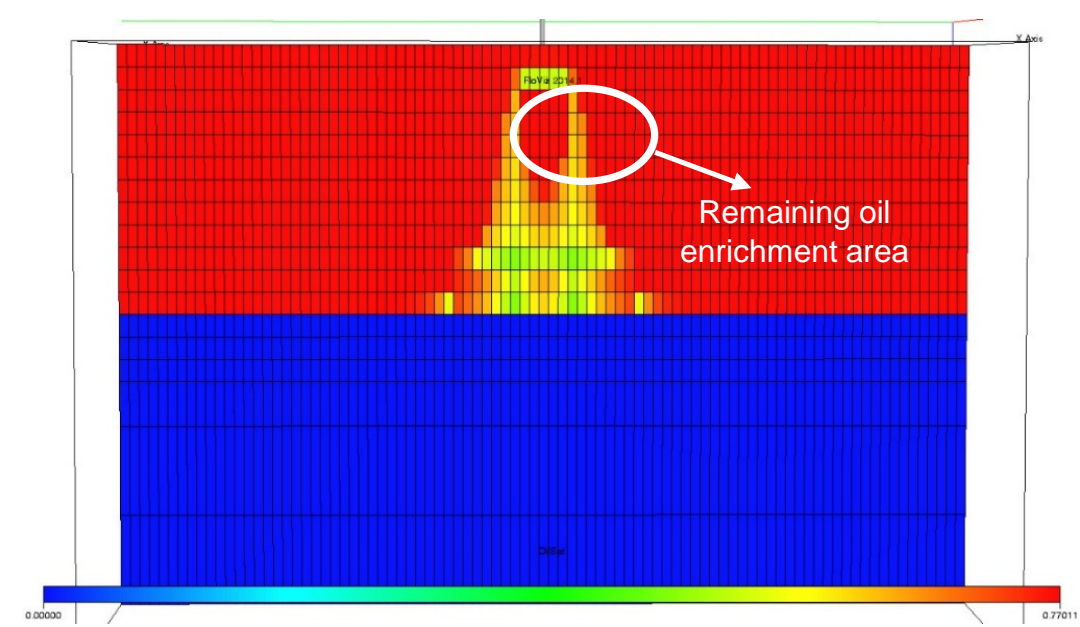

Figure 10. Remaining oil enrichment area in the lower part of interlayer.

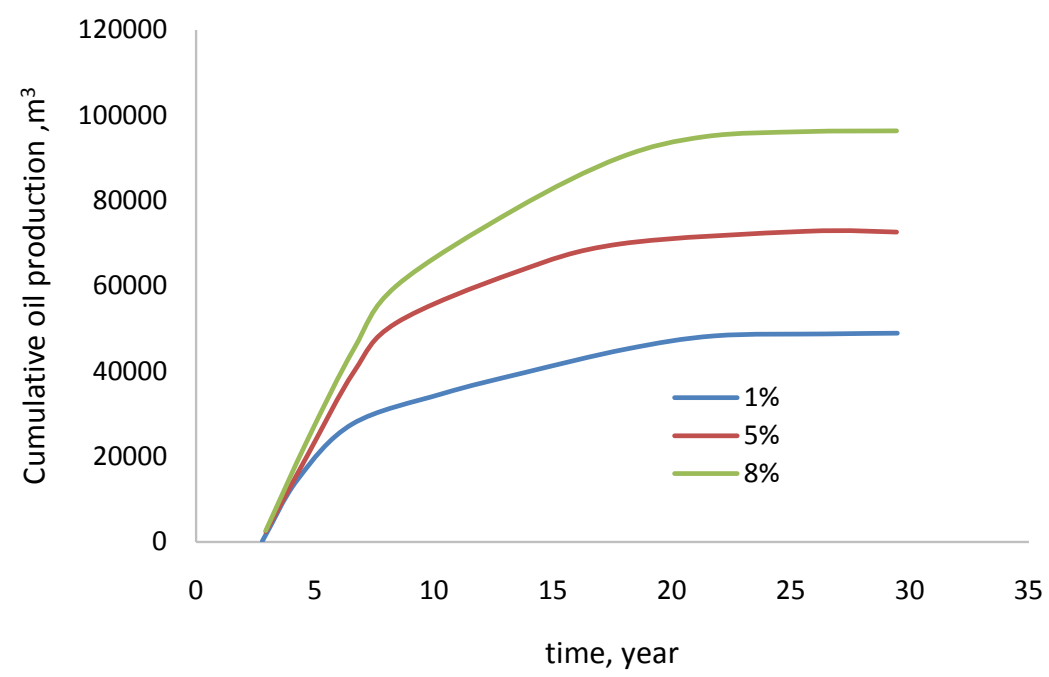

Figure 11. Cumulative oil production of different interlayer sizes.

Table 1. Factor level table of orthogonal test.

\begin{tabular}{ccccccc}
\hline level & $\begin{array}{c}\text { A: Well } \\
\text { spacing }(\mathrm{m})\end{array}$ & B: $\mathrm{K}_{\mathrm{v}} / \mathrm{K}_{\mathrm{h}}$ & $\begin{array}{c}\text { C: Fluid } \\
\text { production }\left(\mathrm{m}^{3} / \mathrm{d}\right)\end{array}$ & $\begin{array}{c}\text { D: Horizontal } \\
\text { well location }\end{array}$ & $\begin{array}{c}\text { E: Viscosity } \\
\text { of crude oil }\end{array}$ & Empty column \\
\hline 1 & 100 & 0.01 & 100 & $0.8 \mathrm{~h}$ & 48 & 1 \\
2 & 200 & 0.05 & 200 & $0.67 \mathrm{~h}$ & 177 & 2 \\
3 & 300 & 0.3 & 300 & $0.3 \mathrm{~h}$ & 666 & 3 \\
\hline
\end{tabular}

Table 2. Range analysis of test results.

\begin{tabular}{ccccccc}
\hline level & A & B & C & D & E & Empty column \\
\hline$R$ & 2 & 10.9 & 5.2 & 4.5 & 15.8 & 4.1 \\
\hline
\end{tabular}

Variance analysis can further eliminate the error size of the test, and accurately obtain the importance of each factor in the test on the test results. The results of variance analysis are shown in Table 3. 
Table 3. Anova table.

\begin{tabular}{ccccccc}
\hline Source of variance & $\begin{array}{c}\text { Sum of squares } \\
\text { of deviations }\end{array}$ & Freedom & Variance & F & Fa & $\begin{array}{c}\text { Significant } \\
\text { level }\end{array}$ \\
\hline Well spacing & 22 & 2 & 11 & - & F0.01(2,8)=8.6 & o \\
Vertical horizontal & 356 & 2 & 178 & 6.3 & F0.05(2,8)=4.5 & $* *$ \\
Fluid production & 88 & 2 & 44 & 1.7 & F0.1(2,8)=3.1 & $* *$ \\
Horizontal well location & 63 & 2 & 32 & 1.2 & F0.25(2,8)=1.7 & $* *$ \\
Oil water viscosity & 801 & 2 & 401 & 14.2 & - & $* * *$ \\
Error & 51 & 2 & 26 & - & - & - \\
The sum & 1383 & - & - & - & - & - \\
\hline
\end{tabular}

Note: "“**” means the most significant; "**” means very significant; "*” means significant; "o" means certain influence.

Through the above range and variance analysis methods, we can get the factors that affect the shape of water ridges. According to the importance degree, the oil-water viscosity ratio $>$ vertical horizontal permeability ratio $>$ liquid production $>$ horizontal well position $>$ well spacing. Among these five factors, the oil-water viscosity ratio accounts for the largest proportion, and the viscosity of most of the main sand bodies in X belongs to the range of heavy oil. Therefore, special attention should be paid in reservoir engineering design The change of oil-water viscosity ratio; the proportion of vertical horizontal permeability ratio, liquid production rate and horizontal well position is slightly lower and the difference among the three degrees is not much; the influence factors of well spacing are the smallest, which indicates that in the later adjustment well deployment, according to the strategy of high-speed development of $\mathrm{x}$ oilfield, the new well pattern can be appropriately infilled in order to quickly obtain economic benefits.

\section{Case Analysis}

According to the understanding of the water ridge shape of horizontal wells in bottom water reservoir, the oil-water viscosity ratio has the greatest influence on the water ridge morphology, and the crude oil viscosity of each sand body in $\mathrm{X}$ oilfield is quite different. Therefore, it is necessary to formulate different well layout optimization plans for the crude oil viscosity of different sand bodies. For sand bodies with different viscosities $(30,80,200,350$ and $500 \mathrm{mPa} \cdot \mathrm{s})$ in X oilfield, different minimum well spacing $(100-300 \mathrm{~m})$ is given when the adjustment well optimization scheme is formulated.

At the same time, according to the water flooded situation of sand body passing through the road well, with the increase of crude oil viscosity, the radius of water ridge becomes smaller, which is consistent with the previous research results.

\section{Conclusions}

Based on the production situation of $\mathrm{X}$ oilfield as the research background, in 
view of the complex water flooding situation in the high water cut stage, the increased risk of sidetracking adjustment wells, and the urgent need to tap the potential of remaining oil, this paper studies the rising law and shape of water ridge of horizontal wells in bottom water reservoir. According to the basic theory of water ridge shape in bottom water reservoir, the mechanism model of horizontal well in bottom water reservoir is established. On this basis, the influencing factors of water ridge of horizontal well in bottom water reservoir are obtained by numerical simulation:

1) With the increase of well spacing, the maximum water ridge radius gradually decreases, the percentage of remaining oil reserves in geological reserves increases, and the development effect becomes worse.

2) The smaller the ratio of vertical permeability to horizontal permeability, the maximum radius of water ridge increases.

3) When the liquid production rate is small, the production pressure difference is small, and the maximum water ridge radius increases with the increase of the liquid production rate. However, because the formation crude oil is heavy oil, the water ridge volume change law is not obvious, and the overall trend is upward, and there is a maximum value. When the production rate exceeds a certain value, the shape of water ridge decreases slightly.

4) The closer the horizontal well is to the bottom water, the bottom water will quickly cone into the bottom of the well; the water breakthrough will be early; the water cut will rise quickly; and the radius of water ridge will be smaller.

5) The shape and size of water ridges were calculated by mechanism model. When the crude oil viscosity is small, the oil-water fluidity is small, which is close to the piston type oil displacement; the water is relatively uniform and the water ridge range is large.

6) With the continuous development of the oilfield, the water cut of the oil well will be higher and higher, and the water ridge will be larger and larger.

7) When the distribution range of the interlayer is larger, the water content rising speed is slower; the shielding effect of interlayer on bottom water is stronger; the recovery degree is higher; and the development effect is better.

This paper analyzes the factors that affect the water ridge shape of horizontal wells in bottom water reservoir, finds out the relationship between the influencing factors and the maximum water ridge radius, and calculates the influence weight of each factor by using the orthogonal test design method, in which the oil-water viscosity ratio has the largest influence proportion. Therefore, it is necessary to pay special attention to the change of oil-water viscosity ratio in reservoir engineering design. The research results provide technical support for remaining oil distribution research and deployment of new adjustment wells.

\section{Conflicts of Interest}

The authors declare no conflicts of interest regarding the publication of this paper. 


\section{References}

[1] Li, C.L. (2005) Principles of Reservoir Engineering. Petroleum Industry Press, Beijing.

[2] Yao, K., Chen, S.Y., Jiang, H.Q., et al. (2009) Research and Application of Critical Production of Horizontal Wells in Water Drive Reservoir. Petroleum Geology and Recovery Factor, 16, 77-80.

[3] Xin, C.P. (2011) Quantitative Description of Water Cone in Bottom Water Reservoir and Optimization of Horizontal Well Pattern Configuration. China University of Petroleum (East China), Dongying.

[4] Xiao, C.Y., Li, W. and Xiao, S.P. (2009) Production Mechanism and Water Cut Rising Law of Edge Bottom Water Reservoir. Fault Block Oil and Gas Field, 16, 68-70.

[5] Lu, C. (2010) Study on Horizontal Bottom Hole Water Inrush. China University of Geosciences, Beijing.

[6] Liu, F. (2012) Study on the Application of Oil-Water Production Data Analysis Technology to Determine the Water Invasion Type of Horizontal Wells. China Information Society, No. 12, 67-68.

[7] Fan, Z.F. and Lin, Z.F. (1994) Study on Critical Production Formula of Horizontal Wells in Bottom Water Drive Reservoir and Its Variation Rule. Petroleum Exploration and Development, No. 1, 65-70.

[8] Hou, J., Cheng, L.S. and Li, C.L. (2006) Calculation of Water Ridge Height of Horizontal Wells in Bottom Water Reservoir. Hydrodynamics Research and Progress, 21, 374-380.

[9] Cao, P., Chang, S.Y., Dai, C.R., et al. (2014) Research Progress of Horizontal Well Water Ridge in Bottom Water Reservoir. Journal of Chongqing University of Science and Technology: Natural Science Edition, 16, 63-66.

[10] Recham, R. (2000) Effects of Water Coning on the Performance of Vertical and Horizontal Wells-A Reservoir Simulation Study of Hassi R'mel Field, Algeria. SPE/CIM International Conference on Horizontal Well Technology, Calgary, Alberta, 6-8 November 2000. https://doi.org/10.2118/65506-MS

[11] Nie, B., Liu, Y.T. and Yang, H.N. (2012) Study on Influencing Factors of Water Coning Rise and Fall in Huan17 Block Bottom Water Reservoir. Special Oil and Gas Reservoir, 19, 84-87.

[12] Liu, Z.Y., Cheng, B., Liu, Y., et al. (2002) Study on Horizontal Well Development: Water Ridge Change and Water Breakthrough Time Prediction of Bottom Water Reservoir. Journal of Northeast Petroleum University, 26, 100-103.

[13] Li, H.Q. and Meng, Y.J. (1994) Simplified Research Model of Horizontal Well Water Ridge Advancement. Journal of Northeast Petroleum University, No. 1, 32-35.

[14] Xiong, X.W., Li, Y.P., Zhang, J.L., et al. (2014) A New Method for Predicting Water Coning Performance and Water Breakthrough Time in Bottom Water Reservoir. Fault Block Oil and Gas Field, 21, 221-223.

[15] Chang, T., Chen, J.B., Liu, J.G., et al. (2020) A Rapid Evaluation Method for Development Potential of Bottom Water Reservoir. Daqing Petroleum Geology and Development, 39, 65-71. 